\title{
Endoscopic direct visualization of gallbladder polypoid lesion using peroral digital single-operator cholangioscopy
}

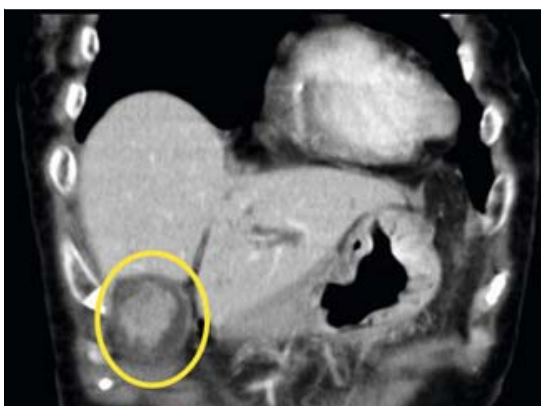

Fig. 1 Contrast-enhanced computed tomography showing a gallbladder tumor (yellow circle) with enhancement, measuring $20 \mathrm{~mm}$.

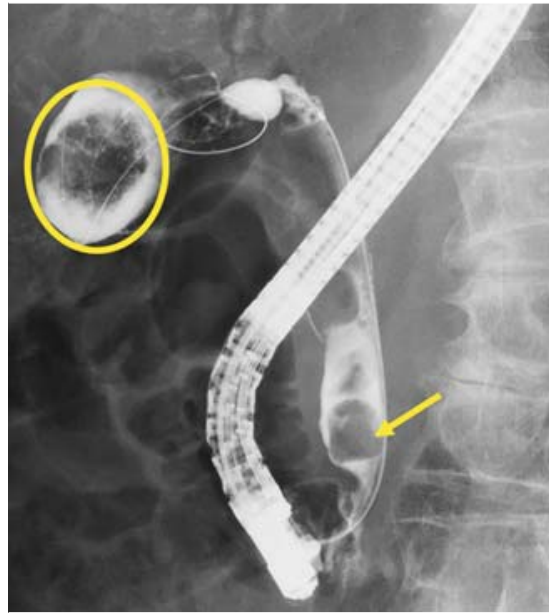

- Fig. 2 Cholangiography showing stones in the common bile duct (arrow) and a gallbladder tumor (yellow circle).

Recently, the SpyGlass (Boston Scientific, Marlborough, Massachusetts, USA) has proven effective in the diagnosis of biliary tract lesions under direct vision [1-3]. However, no reports have evaluated its usefulness in the gallbladder. Gallbladder polypoid lesions include neoplasms and a variety of benign inflammatory, granular, and hyperplastic lesions. Distinguishing between these lesions is often difficult [4], and so a novel diagnostic tool is required. This report describes the first case to our knowledge of a gallbladder

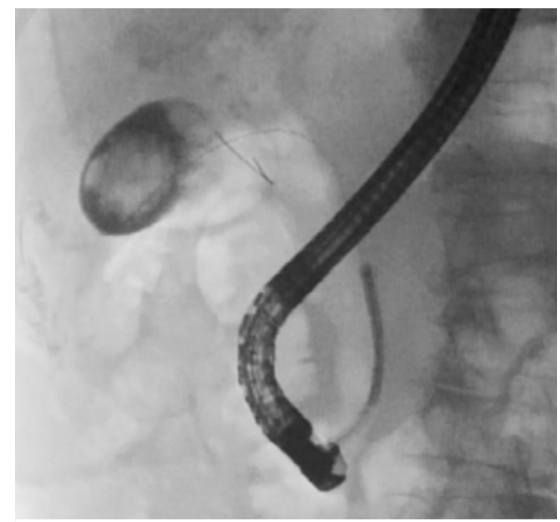

Fig. 3 Fluoroscopic image showing the cystic duct straightened by the guidewire.

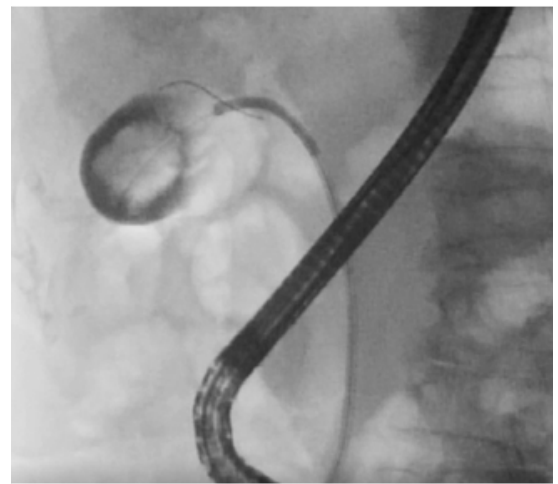

-Fig. 4 Fluoroscopic image showing the SpyGlass cholangioscope advanced into the gallbladder.

polypoid lesion being successfully visualized directly using the Spyglass.

An 85-year-old woman presented with acute cholangitis related to common bile duct (CBS) stones. Contrast-enhanced computed tomography (CT) showed a suspicious gallbladder tumor with enhancement, measuring $20 \mathrm{~mm}$ ( $>$ Fig. 1). Endoscopic retrograde cholangiopancreatography (ERCP) was performed to remove the $C B D$ stones and to collect bile for cytological diagnosis of the gallbladder tumor. After achieving selective bile duct cannulation, a guidewire (Visiglide2; Olympus, Tokyo, Japan) was advanced into the cystic duct and gallblad-

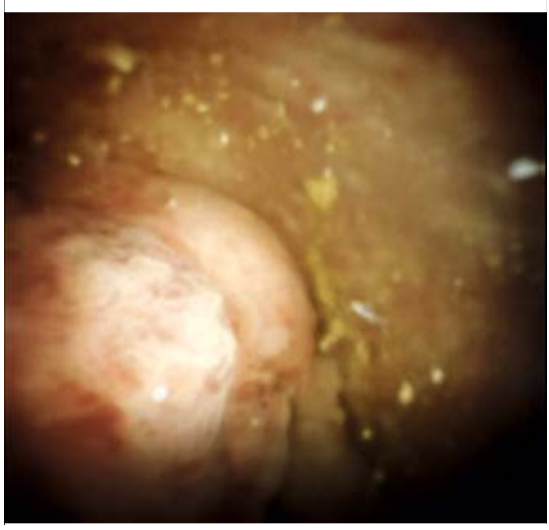

- Fig. 5 Cholangioscopy showing a nodular elevated lesion at the gallbladder fundus, which was suspected to be a malignant tumor.

der. Cholangiography showed stones in the CBD and a tumor in the gallbladder (• Fig.2). With endoscopic papillary large-balloon dilation, the stones were successfully removed. Subsequently, we attempted the following approach for the gallbladder. First, bile was obtained for cytology via a catheter, and then the SpyGlass cholangioscope was inserted into the gallbladder. Because the cystic duct was straightened by the guidewire ( Fig.3), the cholangioscope easily passed through the cystic duct and advanced into the gallbladder ( $>$ Fig.4).

Cholangioscopy identified a nodular elevated lesion at the gallbladder fundus, suspected of being a malignant tumor ( Fig. 5; V Video 1). However, targeted biopsy failed because the forceps could not pass through the curved cholangioscope. Although cytology was negative for malignancy, we recommended surgery based on CT and cholangioscopic findings, but the patient declined on the basis of advanced age.

In summary, although further instrumental improvement is required, SpyGlass cholangioscopy may be an alternative option for diagnosing gallbladder lesions. 


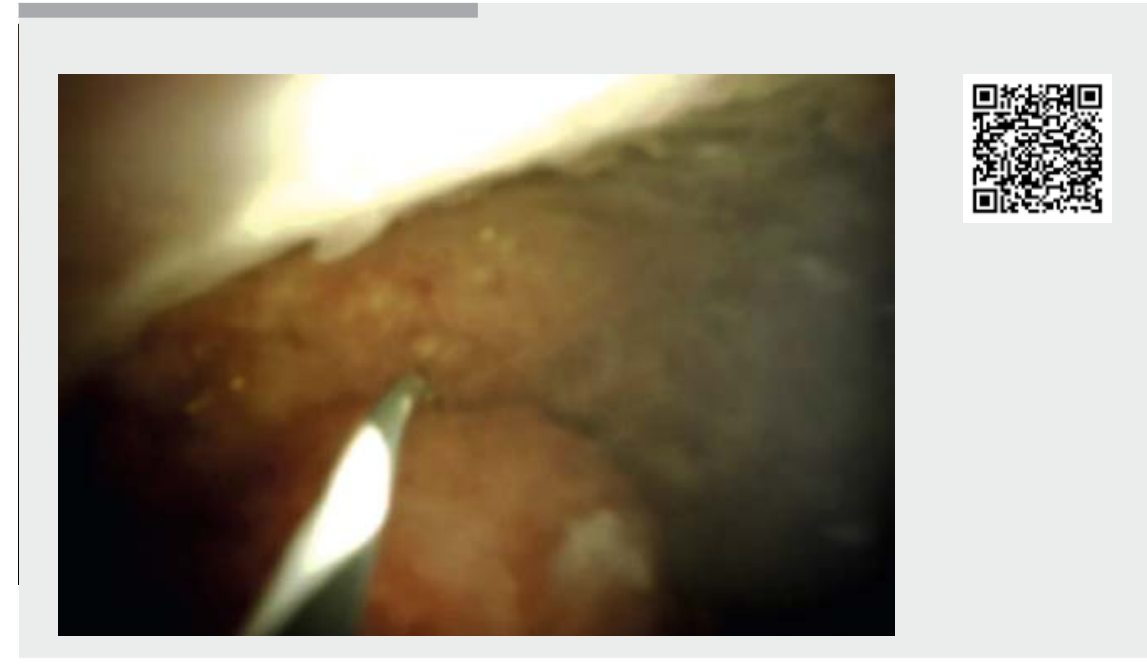

Video 1 The SpyGlass cholangioscope inserted into the gallbladder of an 85-year-old woman identified a nodular elevated tumor under direct vision.

Endoscopy_UCTN_Code_CCL_1AZ_2AC

\section{Acknowledgment}

We thank Jane Charbonneau, DVM, from Edanz Group, for editing a draft of this manuscript.

\section{Competing interests}

The authors declare that they have no conflict of interest.

The authors

\section{Hideki Kamada', Hideki Kobara' ${ }^{1}$, Hiroki} Yamana ${ }^{1}$, Keiichi Okano ${ }^{2}$, Yasuyuki Suzuki ${ }^{2}$, Naoki Fujita ${ }^{1}$, Tsutomu Masaki ${ }^{1}$

1 Department of Gastroenterology and Neurology, Faculty of Medicine, Kagawa University, Kagawa, Japan

2 Department of Gastroenterological Surgery, Faculty of Medicine, Kagawa University, Kagawa, Japan
[4] Wiles R, Thoeni RF, Barbu ST et al. Management and follow-up of gallbladder polyps: joint guidelines between the European Society of Gastrointestinal and Abdominal Radiology (ESGAR), European Association for Endoscopic Surgery and other Interventional Techniques (EAES), International Society of Digestive Surgery - European Federation (EFISDS) and European Society of Gastrointestinal Endoscopy (ESGE). Eur Radiol 2017; 27: 3856-3866

\section{Bibliography}

Endoscopy 2021; 53: E263-E264

DOI 10.1055/a-1252-2704

ISSN 0013-726X

published online 1.10 .2020

(c) 2020. Thieme. All rights reserved.

Georg Thieme Verlag KG, Rüdigerstraße 14, 70469 Stuttgart, Germany

\section{ENDOSCOPY E-VIDEOS \\ https://eref.thieme.de/e-videos}

\section{Hideki Kamada, MD, PhD}

Department of Gastroenterology and Neurology, Faculty of Medicine, Kagawa University, 1750-1 Ikenobe, Miki, Kita, Kagawa 761-0793, Japan

Fax: +81-87-8912158

kamacho@med.kagawa-u.ac.jp

\section{References}

[1] Kahaleh M. Spyglass direct visualization system. Clin Endosc 2012; 45: 316-318

[2] Kurihara T, Yasuda I, Isayama H et al. Diagnostic and therapeutic single-operator cholangiopancreatoscopy in biliopancreatic diseases: Prospective multicenter study in Japan. World J Gastroenterol 2016; 22: 1891-1901

[3] Rey JW, Hansen T, Dümcke $S$ et al. Efficacy of SpyGlass (TM)-directed biopsy compared to brush cytology in obtaining adequate tissue for diagnosis in patients with biliary strictures. World J Gastrointest Endosc 2014; 6: 137-143

\section{CORRECTION}

Endoscopic direct visualization of gallbladder polypoid lesion using peroral digital single-operator cholangioscopy

Kamada H, Kobara H, Yamana $\mathrm{H}$ et al. Endoscopic direct visualization of gallbladder polypoid lesion using peroral digital single-operator cholangioscopy.

Endoscopy 2020, 52:

10.1055/a-1252-2704

In the above-mentioned article, the title has been corrected. Correct is: Endoscopic direct visualization of gallbladder polypoid lesion using peroral digital single-operator cholangioscopy. This was corrected in the online version on May 6, 2021. 